\title{
Analisis Pengaruh Beban Terhadap Efisiensi Generator Unit 2 PLTP PT. Indonesia Power UPJP Kamojang
}

\author{
Muharrir $^{1}$; Ibnu Hajar ${ }^{2}$ \\ ${ }^{1,2}$ Sekolah Tinggi Teknik PLN \\ ${ }^{1}$ muharrir97@gmail.com, ${ }^{2 i b n u . h a j a r @ s t t p l n . a c . i d ~}$
}

\begin{abstract}
Geothermal as a newest natural resource for Indonesian. PLTP PT. Indonesia Power as one of subsidiaries of PLN that is focused on generating using geothermal resource. One of the important components in the system of PLTP is a generator. PLTP Kamojang had been operating for about \pm 30 years, where there are still some problems that will reduce the efficiency of generator. The generator at PLTP Kamojang unit 2 must be operated more than $90 \%$ so that it will be able to supply electric power for $150 \mathrm{kV}$. If the generator operated with the efficiency under $80 \%$, so the supply of energy will not be maximum, because there are so much energy of electric lost caused by the losses in the generator. That is why needs to be analyzed toward the efficiency of the generator, whether the generator still works optimum or not. The result of analyses from the month of February 2019 as long as 1 month, found that the efficiency of generator unit 2 is about 92,89\%. If comparing by the efficiency of generator as design as much as 98,4\%. The efficiency value of the generator unit 2 Kamojang is decreased for about 5,51\%. This condition showed that the generator still reliable one in supllying electric power.
\end{abstract}

Keywords: PLTP, Generator, efficiency

\begin{abstract}
ABSTRAK
Panas bumi merupakan salah satu sumber daya terbarukan yang paling potensial untuk Indonesia. PLTP PT. Indonesia Power merupakah salah satu anak perusahaan PT. PLN yang bergerak di bidang pembangkitan dengan memanfaatkan sumber panas bumi. Salah satu komponen penting dalam sistem PLTP adalah generator. Kondisi PLTP Kamojang saat ini sudah beroperasi \pm 30 tahun, dimana terdapat banyak permasalahan yang dapat menurunkan efisiensi generator. Generator pada PLTP unit 2 Kamojang harus beroperasi diatas 90\% agar dapat mensupply energi listrik ke jaringan $150 \mathrm{kV}$. Jika generator beroperasi dengan efisiensi dibawah $80 \%$ maka energi yang dialirkan tidak maksimal karena banyak energi listrik yang hilang akibat rugi-rugi pada generator. Oleh karena itu perlu dilakukan analisa terhadap efisiensi generator apakah generator masih dalam keadaan optimal atau kurang optimal. Hasil dari analisa dengan mengambil data pada tanggal bulan Februari 2019 selama 1 bulan didapatkan efisiensi rata-rata generator unit 2 sebesar 92,89\%. Apabila dibandingkan dengan efisiensi generator secara desain sebesar 98,4\%, nilai efisiensi generator unit 2 Kamojang mengalami penurunan sebesar 5,51\%. Hal ini menunjukkan bahwa generator masih memiliki keandalan kinerja yang baik sebagai penghasil daya listrik.
\end{abstract}

Kata kunci: PLTP, Generator, Efisiensi 


\section{KILAT}

Vol. 8, No. 2, Oktober 2019, P-ISSN 2089-1245, E-ISSN 2655-4925

\section{PENDAHULUAN}

Indonesia merupakan negara berkembang yang menjadikan teknologi sebagai sebuah peluang untuk mendorong pertumbuhan ekonomi. Panas bumi merupakan salah satu sumber daya terbarukan yang paling potensial untuk Indonesia. PT. Indonesia Power UPJP Kamojang merupakan salah satu anak perusahaan PT PLN di Indonesia yang bergerak di bidang pembangkitan energi listrik dengan memanfaatkan sumber panas bumi yang memasok daya sebesar $375 \mathrm{MW}$ dimana dibagi menjadi tiga unit PLTP diantaranya, unit PLTP Kamojang (140 MW), unit PLTP Darajat (55 MW), dan unit PLTP Gunung Salak (180 MW). Pembangkit unit PLTP Kamojang memiliki tiga buah unit pembangkit listrik dengan daya diantaranya sebesar, unit 1 (30 MW), unit 2 (55 MW), dan unit 3 (55 MW). Salah satu komponen penting dalam sistem PLTP adalah generator. Generator merupakan suatu sistem yang berfungsi untuk mengubah tenaga mekanik menjadi tenaga listrik. Pada generator banyak terdapat masalah-masalah yang timbul termasuk permasalahan efisiensi generator. Gangguan efisiensi generator dapat berakibat fatal pada generator sehingga dapat menyebabkan generator tidak bekerja secara optimal dan sistem kelistrikan konsumen akan padam. Efisiensi pada generator akan mempengaruhi kinerja dari sistem PLTP. Semakin besar efisiensi generatornya maka keandalan sistem juga semakin baik.

Pada jurnal yang berjudul analisa perhitungan efisiensi turbin generator qfsn-300-2-20B unit 10 dan 20 di PT. PJB UBJOM PLTU Rembang, membahas tentang perhitungan efisiensi generator dengan data nilai rata-rata daya yang dibangkitkan generator PLTU Rembang unit 10 dan 20 dalam 24 jam selama 10 hari. Pada penelitian tersebut didapat hasil bahwa nilai dari efisiensi generator unit 10 dan 20 PLTU rembang mengalami penurunan sebesar $\pm 5 \%$. (Cahyadi, 2015).

Penelitian mengenai pengaruh beban terhadap efisiensi generator pernah dilakukan pada tahun 2018 yang berjudul analisis pengaruh beban terhadap efisiensi generator pada PLTU PT. Lestari Banten Energi. Dalam skripsi tersebut dilakukan penelitian dari tanggal 1 januari 2018 sampai 5 januari 2018 dan didapatkan hasil rata-rata efisiensi perhari pada generator tersebut berkisar 98\%99\%. (Hidayat, 2018).

Pada penelitian mengenai efisiensi pada generator terhadap beban, penulis melakukan penelitian dengan objek studi pada generator PLTP PT. Indonesia Power Kamojang.

Tujuan dilakukan penelitian ini untuk menganalisis perbandingan efisiensi aktual generator unit 2 dengan nilai efisiensi desain.

\section{METODE/PERANCANGAN PENELITIAN}

\subsection{Metode Penelitian}

Penelitian ini menggunakan jenis penelitian kuantitatif, karena untuk menganalisis efisiensi generator terhadap pengaruh beban yang berubah dibutuhkannya data yang relevan seperti data pembebanan pada generator, data laju aliran massa steam turbin, data spesifikasi generator dan data spesifikasi turbin. 


\subsection{Data Generator dan Turbin}

Tabel 1. Spesifikasi Generator

\begin{tabular}{|l|l|}
\hline Manufaktur & Mitsubishi Electric Corporation \\
\hline Tipe & AAA145B0101 \\
\hline Kapasitas & $55 \mathrm{MW} / 68750 \mathrm{kVA}$ \\
\hline Tegangan & $11800 \mathrm{~V}$ \\
\hline Arus & $3364 \mathrm{~A}$ \\
\hline Phase & 3 \\
\hline Power Factor & 0.85 \\
\hline Frekuensi & $50 \mathrm{~Hz}$ \\
\hline Rugi Daya Disipasi Pendingin & $1050 \mathrm{KW}$ \\
\hline Resistansi Stator & $0.00305 \mathrm{ohm}$ \\
\hline Resistansi Rotor & $0.174 \mathrm{ohm}$ \\
\hline
\end{tabular}

Tabel 2. Spesifikasi Turbin

\begin{tabular}{|l|l|}
\hline Manufaktur & Mitsubishi Heavy Industry. Ltd \\
\hline Tipe & Impulse and reaction double flow \\
\hline Kapasitas & $55 \mathrm{MW}$ \\
\hline Rotasi & $3000 \mathrm{rpm}$ \\
\hline Arah Putaran & Searah jarum jam \\
\hline Tekanan uap masuk & 6.5 bar \\
\hline Tekanan uap keluar & 0.1 bar \\
\hline
\end{tabular}

\subsection{Data Pembebanan Generator}

Data penelitian ini merupakan data pembebanan generator unit 2 di PLTP PT. Indonesia Power UPJP Kamojang. Data yang diambil teracatat dari tanggal 1 Februari 2019 sampai 28 Februari 2019.

Tabel 3. Data Pembebanan Generator bulan Februari 2019

\begin{tabular}{|c|c|c|c|c|c|c|c|}
\hline $\begin{array}{c}\text { Hari } \\
\text { ke- }\end{array}$ & $\begin{array}{c}\text { Beban } \\
(\mathrm{MW})\end{array}$ & $\begin{array}{c}\text { Faktor } \\
\text { Daya } \\
(\cos \varphi)\end{array}$ & $\begin{array}{c}\text { Beban } \\
(\mathrm{MVA})\end{array}$ & $\begin{array}{c}\text { Arus } \\
(\mathrm{A})\end{array}$ & $\begin{array}{c}\text { Arus } \\
\text { Eksitasi } \\
(\mathrm{A})\end{array}$ & $\begin{array}{c}\text { Frekuensi } \\
(\mathrm{Hz})\end{array}$ & $\begin{array}{c}\text { Tegangan } \\
(\mathrm{kV})\end{array}$ \\
\hline 1 & 55 & 0.98 & 56.12 & 2745 & 440 & 50 & 11.8 \\
\hline 2 & 55.5 & 0.98 & 56.63 & 2753 & 439 & 50 & 11.8 \\
\hline 3 & 55 & 0.98 & 56.12 & 2734 & 430 & 50 & 11.8 \\
\hline 4 & 54.9 & 0.98 & 56.02 & 2738 & 440 & 50 & 11.8 \\
\hline 5 & 55 & 0.97 & 56.70 & 2743 & 443 & 50 & 11.8 \\
\hline 6 & 55 & 0.98 & 56.12 & 2746 & 441 & 50 & 11.8 \\
\hline 7 & 55.1 & 0.97 & 56.80 & 2760 & 453 & 50 & 11.8 \\
\hline 8 & 55.3 & 0.98 & 56.43 & 2743 & 432 & 50 & 11.8 \\
\hline 9 & 54.9 & 0.97 & 56.60 & 2751 & 440 & 50 & 11.8 \\
\hline 10 & 55 & 0.98 & 56.12 & 2717 & 417 & 50 & 11.8 \\
\hline
\end{tabular}




\begin{tabular}{|l|c|c|c|c|c|c|c|}
\hline 11 & 55.2 & 0.98 & 56.33 & 2731 & 417 & 50 & 11.8 \\
\hline 12 & 55.1 & 0.98 & 56.22 & 2727 & 426 & 50 & 11.8 \\
\hline 13 & 55 & 0.98 & 56.12 & 2732 & 432 & 50 & 11.8 \\
\hline 14 & 54.8 & 0.98 & 55.92 & 2722 & 425 & 50 & 11.8 \\
\hline 15 & 54.7 & 0.97 & 56.39 & 2727 & 433 & 50 & 11.8 \\
\hline 16 & 54.6 & 0.97 & 56.29 & 2741 & 451 & 50 & 11.8 \\
\hline 17 & 54.8 & 0.98 & 55.92 & 2703 & 421 & 50 & 11.8 \\
\hline 18 & 54.6 & 0.98 & 55.71 & 2695 & 415 & 50 & 11.8 \\
\hline 19 & 54.3 & 0.97 & 55.98 & 2734 & 444 & 50 & 11.8 \\
\hline 20 & 54.7 & 0.98 & 55.82 & 2717 & 431 & 50 & 11.8 \\
\hline 21 & 54.6 & 0.98 & 55.71 & 2708 & 429 & 50 & 11.8 \\
\hline 22 & 54.4 & 0.98 & 55.51 & 2706 & 431 & 50 & 11.8 \\
\hline 23 & 54.4 & 0.98 & 55.51 & 2714 & 434 & 50 & 11.8 \\
\hline 24 & 54.5 & 0.98 & 55.61 & 2713 & 435 & 50 & 11.8 \\
\hline 25 & 54.2 & 0.98 & 55.31 & 2604 & 431 & 50 & 11.8 \\
\hline 26 & 54.4 & 0.97 & 56.08 & 2739 & 448 & 50 & 11.8 \\
\hline 27 & 54.4 & 0.97 & 56.08 & 2717 & 428 & 50 & 11.8 \\
\hline 28 & 54.6 & 0.97 & 56.29 & 2729 & 443 & 50 & 11.8 \\
\hline
\end{tabular}

\subsection{Data Tekanan dan Laju Uap pada Turbin}

Berikut ini merupakan data laju uap, tekanan uap masuk dan tekanan uap keluar di PLTP PT. Indonesia Power UPJP Kamojang unit 2 pada tanggal 1 Ferbruari 2019 sampai 28 Februari 2019:

Tabel 4. Data Sistem Uap dan Turbin Bulan Februari 2019

\begin{tabular}{|c|c|c|c|}
\hline $\begin{array}{c}\text { Hari } \\
\text { Ke- }\end{array}$ & $\begin{array}{c}\text { Laju Uap } \\
(\mathrm{Kg} / \mathrm{s})\end{array}$ & $\begin{array}{c}\text { Tekanan Uap } \\
\text { Masuk }(\mathrm{kPa})\end{array}$ & $\begin{array}{c}\text { Tekanan Uap Keluar } \\
(\mathrm{kPa})\end{array}$ \\
\hline 1 & 119.00 & 528.5 & 11.6699 \\
\hline 2 & 119.22 & 525.2 & 11.2561 \\
\hline 3 & 118.39 & 522.7 & 11.6233 \\
\hline 4 & 118.25 & 525.4 & 12.1028 \\
\hline 5 & 118.56 & 526.6 & 11.8758 \\
\hline 6 & 119.36 & 529.8 & 11.8758 \\
\hline 7 & 119.47 & 523.5 & 11.4614 \\
\hline 8 & 118.92 & 526.8 & 11.2787 \\
\hline 9 & 118.06 & 529.5 & 11.4614 \\
\hline 10 & 118.53 & 533.4 & 11.3355 \\
\hline 11 & 119.00 & 536.4 & 11.1433 \\
\hline 12 & 118.90 & 536.9 & 11.0483 \\
\hline 13 & 118.06 & 526.5 & 11.1321 \\
\hline 14 & 118.19 & 539.8 & 11.2617 \\
\hline
\end{tabular}




\begin{tabular}{|l|l|l|l|}
\hline 15 & 118.58 & 538.7 & 11.8049 \\
\hline 16 & 120.36 & 538.9 & 11.6933 \\
\hline 17 & 121.22 & 539.8 & 11.8877 \\
\hline 18 & 121.03 & 539.9 & 11.3869 \\
\hline 19 & 121.17 & 537.7 & 12.0848 \\
\hline 20 & 120.89 & 539.6 & 12.3458 \\
\hline 21 & 120.50 & 542.4 & 11.8344 \\
\hline 22 & 121.50 & 544.3 & 11.9352 \\
\hline 23 & 121.33 & 544.8 & 12.2908 \\
\hline 24 & 120.14 & 543.2 & 11.6699 \\
\hline 25 & 120.81 & 542.2 & 12.0908 \\
\hline 26 & 120.86 & 542.9 & 11.7813 \\
\hline 27 & 121.69 & 544.1 & 11.6641 \\
\hline 28 & 121.11 & 541.3 & 12.0667 \\
\hline
\end{tabular}

\subsection{Perhitungan Entalpi dan Entropi}

Untuk mendapatkan nilai entalpi dan entropi pada penelitian ini dapat menggunakan steam table yang bersifat saturated (lampiran tertera). Pada perhitungan ini dapat menggunakan cara interpolasi dimana hal ini dimaksud untuk menentukan nilai yang berada diantara dua nilai yang diketahui. Interpolasi ini didasarkan pada teori perbandingan. Adapun pada penelitian ini perbandingan yang dilakukan antara nilai tekanan uap masuk turbin dengan entalpi saturated vapor $\left(\mathrm{h}_{1}\right)$, nilai tekanan uap masuk turbin dengan entropi saturated vapor $\left(\mathrm{s}_{1}\right)$, nilai tekanan uap keluar turbin dengan entalpi saturated liquid $\left(\mathrm{h}_{\mathrm{f}}\right)$, tekanan uap keluar tubin dengan entalpi saturated vapor $\left(\mathrm{h}_{\mathrm{g}}\right)$, tekanan uap keluar turbin dengan entropi saturated liquid $\left(\mathrm{s}_{\mathrm{f}}\right)$ dan tekanan uap keluar turbin dengan entropi saturated vapor $\left(\mathrm{s}_{\mathrm{g}}\right)$.

$$
\frac{\left(x-x_{1}\right)}{\left(x_{2}-x_{1}\right)}=\frac{\left(y-y_{1}\right)}{\left(y_{2}-y_{1}\right)}
$$

Adapun untuk mempermudah perhitungan entalpi dan entropi dapat menggunakan aplikasi. Aplikasi yang digunakan untuk mempermudah perhitungan yaitu menggunakan software SteamTab. Aplikasi ini merupakan perangkat lunak yang menyediakan data yang akurat seperti nilai entalpi, dan entropi pada kondisi saturated maupun pada kondisi superheated. Berikut ini merupakan hasil perhitungan entalpi dan entropi berdasarkan tekanan uap masuk turbin dan tekanan uap keluar turbin menggunakan aplikasi SteamTab. 


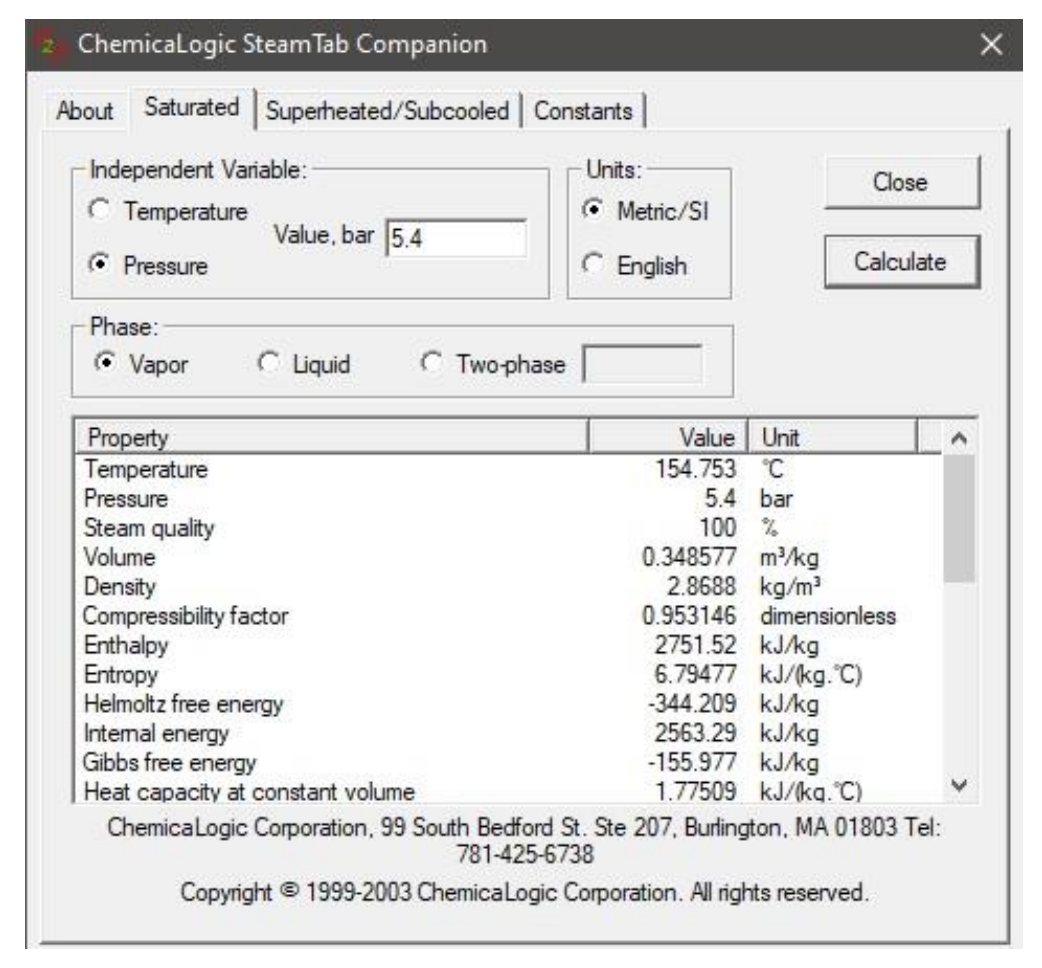

Gambar 1. Tampilan Aplikasi steamtab pada tekanan 5.4 bar

\subsection{Perhitungan Daya Keluaran Turbin}

Untuk menghitung nilai daya keluaran turbin (output) pada PLTP PT. Indonesia Power unit Kamojang dapat dihitung menggunakan beberapa rumus berikut:

1. Mencari nilai kualitas uap (x)

Untuk mencari nilai dari kualitas uap dapat menggunakan persamaan:

$x=\frac{s_{1}-s_{f}}{s_{g}-s_{f}}$

Dimana:

$\mathrm{S}_{1}=$ nilai entropi berdasarkan tekanan uap masuk turbin

$\mathrm{S}_{\mathrm{f}}=$ nilai entropi saturated liquid berdasarkan tekanan uap keluar turbin

$\mathrm{S}_{\mathrm{g}}=$ nilai entropi saturated vapor berdasarkan tekanan uap keluar turbin

2. Mencari nilai entalpi keluar turbin dalam kondisi isentropis $\left(\mathrm{h}_{2} \mathrm{~s}\right)$

Untuk mencari nilai entalpi keluaran turbin dalam kondisi isentropis dapat menggunakan persamaan berikut:

$h_{2} s=h_{f}+x .\left(h_{g}-h_{f}\right)$

Dimana:

$\mathrm{h}_{\mathrm{f}}=$ nilai entalpi saturated liquid berdasarkan tekanan uap keluar turbin

$\mathrm{x}=$ nilai kualitas uap

$\mathrm{h}_{\mathrm{g}}=$ nilai entalpi saturated vapor berdasarkan tekanan uap keluar turbin

3. Mencari nilai daya isentropis (W isentropis)

Untuk menghitung nilai daya isentropis dapat menggunakan persamaan:

$W_{\text {isentropis }}=\dot{\mathrm{m}} \cdot\left(h_{1}-h_{2} s\right)$ 
Dimana:

$\dot{\mathrm{m}}=$ laju aliran uap

$\mathrm{h}_{1}=$ entalpi berdasarkan uap masuk turbin

$\mathrm{h}_{2} \mathrm{~S}=$ entalpi keluar turbin dalam kondisi isentropis

4. Mencari nilai daya aktual (W aktual)

Adapun cara untuk menghitung nilai daya aktual adalah dengan menggunakan persamaan berikut ini:

$W_{\text {aktual }}=\eta_{\text {turbin }} x W_{\text {isentropis }}$

Dimana:

$\eta_{\text {turbin }}=$ efisiensi turbin

$\mathrm{W}_{\text {isentropis }}=$ daya isentropis

\subsection{Perhitungan Daya Keluaran Turbin}

Besarnya nilai efisiensi generator dapat dihitung menggunakan persamaan berikut:

$\eta=\frac{\text { Pout }}{\text { Pin }} \times 100 \%$

Dimana:

$\eta \quad=$ efisiensi generator

Pout = daya keluaran generator $(\mathrm{MW})$

Pin = daya masukan generator $(\mathrm{MW})$

\section{HASIL DAN PEMBAHASAN}

Untuk mendapatkan nilai dari efisiensi generator dapat dilakukan dengan menentukan daya keluaran (output) dan juga daya masukan (input) dengan menggunakan rumus yang sudah dijelaskan.

Tabel 5. Data Perhitungan Efisiensi Generator menggunakan aplikasi

\begin{tabular}{|c|c|c|c|}
\hline Jam & Pout (MW) & Pin (MW) & $\begin{array}{c}\text { Efisiensi } \\
\text { Generator }\end{array}$ \\
\hline 1 & 55.0 & 58.528 & $93.972 \%$ \\
\hline 2 & 55.5 & 58.767 & $94.441 \%$ \\
\hline 3 & 55 & 57.956 & $94.900 \%$ \\
\hline 4 & 54.9 & 57.888 & $94.838 \%$ \\
\hline 5 & 55 & 57.978 & $94.864 \%$ \\
\hline 6 & 55 & 58.369 & $94.228 \%$ \\
\hline 7 & 55.1 & 58.422 & $94.314 \%$ \\
\hline 8 & 55.3 & 58.866 & $93.942 \%$ \\
\hline 9 & 54.9 & 58.153 & $94.406 \%$ \\
\hline 10 & 55 & 58.706 & $93.687 \%$ \\
\hline 11 & 55.2 & 59.282 & $93.114 \%$ \\
\hline 12 & 55.1 & 59.273 & $92.960 \%$ \\
\hline 13 & 55 & 58.494 & $94.027 \%$ \\
\hline 14 & 54.8 & 58.859 & $93.104 \%$ \\
\hline
\end{tabular}




\begin{tabular}{|c|c|c|c|}
\hline 15 & 54.7 & 58.356 & $93.735 \%$ \\
\hline 16 & 54.6 & 59.276 & $92.111 \%$ \\
\hline 17 & 54.8 & 59.633 & $91.895 \%$ \\
\hline 18 & 54.6 & 69.979 & $91.032 \%$ \\
\hline 19 & 54.3 & 59.271 & $91.613 \%$ \\
\hline 20 & 54.7 & 59.052 & $92.630 \%$ \\
\hline 21 & 54.6 & 59.32 & $92.043 \%$ \\
\hline 22 & 54.4 & 59.826 & $90.930 \%$ \\
\hline 23 & 54.4 & 59.332 & $91.687 \%$ \\
\hline 24 & 54.5 & 59.457 & $91.663 \%$ \\
\hline 25 & 54.2 & 59.374 & $91.286 \%$ \\
\hline 26 & 54.4 & 59.521 & $91.396 \%$ \\
\hline 27 & 54.4 & 60.233 & $90.316 \%$ \\
\hline 28 & 54.6 & 59.523 & $91.729 \%$ \\
\hline Rata-rata & 54.8 & 59.3 & $92.888 \%$ \\
\hline
\end{tabular}

Pada tabel 5 dapat dilihat bahwa nilai efisiensi terendah terjadi tanggal 27 Februari 2019 dengan efisiensi sebesar $90.32 \%$, sedangkan nilai efisiensi tertinggi terjadi pada tanggal 3 Februari 2019 dengan efisiensi sebesar $94.90 \%$.

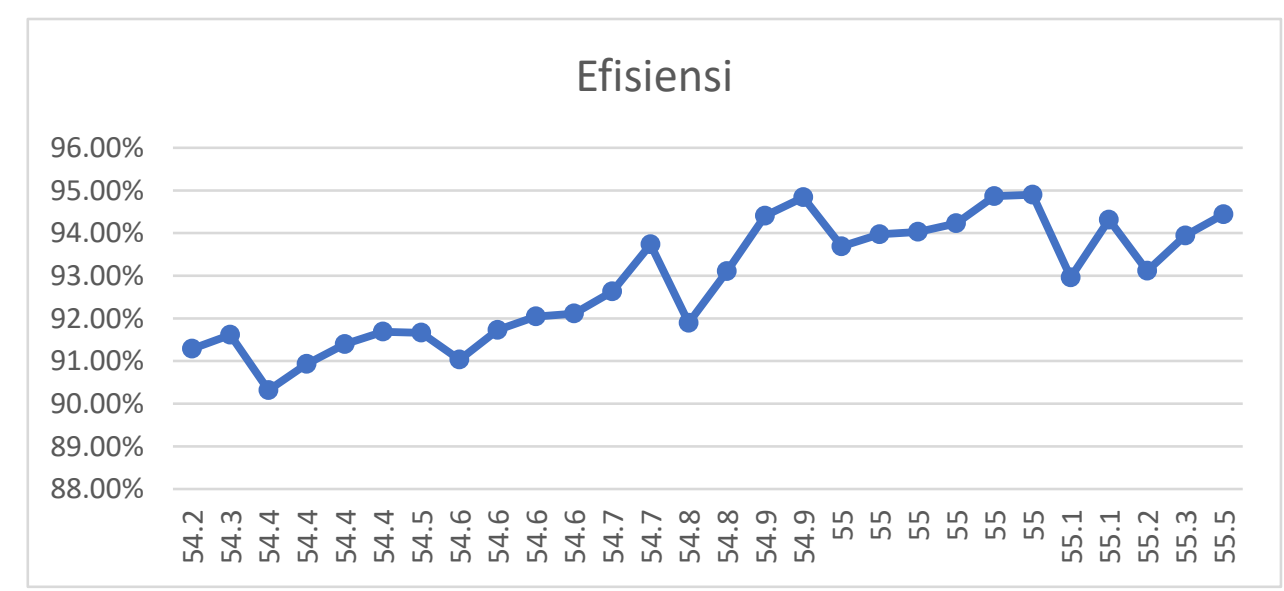

Gambar 2. Grafik efisiensi generator dengan perhitungan aplikasi

Dalam mengkonversikan energi mekanis menjadi energi listrik, generator mengalami kehilangan daya (losses), oleh karena itu efisiensi generator tidak bisa mencapai 100\%. Pada buku Electric Machinery Fundamentals, SJ. Chapman dijelaskan bahwa terdapatnya rugi-rugi generator, diantaranya rugi-rugi panas pada kumparan (winding), rugi-rugi pada inti generator (core), serta rugirugi mekanik akibat gesekan terhadap udara pada saat berputar. Rugi-rugi panas yang dihasilkan dari inti dan kumparan generator dipengaruhi oleh sistem pendingin generator. Oleh karena itu terdapatnya perubahan efisiensi generator saat beroperasi.

Berdasarkan tabel 5 didapatkan nilai rata-rata efisiensi generator pada unit 2 sebesar $92.88 \%$, dengan beban rata-rata 54.8 MW dan daya masukan rata-rata 59.3 MW. Pada manual book generator unit 2 nilai efisiensi generator secara desain dengan beban 55 MW sebesar 98.4\%. Apabila 
menggunakan persamaan efisiensi generator untuk mencari nilai daya input, maka didapat nilai input saat beban $55 \mathrm{MW}$ dengan efisiensi sesuai manual book $98.4 \%$.

$$
\begin{aligned}
\text { Pin } & =\frac{\text { Beban }}{\eta \text { generator }} \times 100 \% \\
& =\frac{55 \mathrm{MW}}{98.4 \%} \times 100 \% \\
& =56 \mathrm{MW}
\end{aligned}
$$

Dari persamaan tersebut dapat dilakukan perbandingan antara daya input dan efisiensi aktual dengan daya input dan efisiensi berdasarkan manual book generator unit 2 saat beban 55 MW. Perbandingan tersebut dapat dilihat pada tabel 6.

Tabel 6. Perbandingan Data Aktual dengan Spesifikasi

\begin{tabular}{|c|c|c|c|}
\hline & Daya Output (MW) & Daya Input (MW) & Efisiensi (\%) \\
\hline spesifikasi & 55 & 56 & 98.4 \\
\hline Aktual & 54.8 & 59.3 & $92.89 \%$ \\
\hline
\end{tabular}

Dari tabel tersebut dapat dilihat pada hasil perhitungan bahwa, daya masukan pada generator sudah mengalami kenaikan sebesar 3.3 MW sehingga efisiensi generator turun 5.51\%. Kenaikan daya masukan dan berkurangnya efisiensi generator dapat disebabkan oleh rugi-rugi tembaganya. Sehingga energi yang seharusnya diubah menjadi energi listrik akan berubah menjadi panas. Selain disebabkan oleh rugi daya pada generator, besar hasil perhitungan efisiensi generator juga dipengaruhi oleh rugi daya mekanis pada kopel turbin generator saat transfer daya antara turbin dan generator.

\section{KESIMPULAN DAN SARAN}

1. Daya masukan dan beban pada generator sinkron unit 2 memiliki efisiensi rata-rata pada bulan Februari 2019 sebesar 92.89\%, dengan nilai efisiensi terendah generator sinkron unit 2 pada tanggal 27 Februari 2019 yaitu sebesar 90,32\%, sedangkan nilai efisiensi generator tertinggi terjadi pada tanggal 3 Februari 2019 sebesar $94.90 \%$.

2. Generator sinkron unit 2 mengalami penurunan efisiensi sebesar $5.51 \%$, hal ini dapat dilihat dari perbandingan efisiensi berdasarkan manual book dengan perhitungan aktual. Efisiensi generator sinkron unit 2 berdasarkan hasil perhitungan rata-rata pada bulan Februari 2019 sebesar 92.89\%, sedangkan efisiensi berdasarkan spesifikasi manual book sebesar 98,4\%.

3. Perhitungan efisiensi pada generator dilakukan untuk mengetahui apakah generator masih dalam kondisi optimal atau tidak agar dapat dilakukannya maintanace.

\section{UCAPAN TERIMAKASIH}

Penulis mengucapkan terima kasih kepada Sekolah Tinggi Teknik PLN dan PT. Indonesia Power UPJP Kamojang yang telah memberi dukungan yang membantu pelaksanaan penelitian dan atau penulisan artikel. 


\section{KILAT}

Vol. 8, No. 2, Oktober 2019, P-ISSN 2089-1245, E-ISSN 2655-4925

\section{DAFTAR PUSTAKA}

[1] Aliansyah, E. (2008). Studi Analisa Daya Keluaran Generator Sinkron Tiga Phasa Dengan Rotor Silinder. Medan: Universitas Sumatra Utara.

[2] Balqis, E. R. (2012). Optimasi Daya Listrik pada PT Pertamina Geothermal Energy Area Kamojang, Jawa Barat. JURNAL TEKNIK POMITS, 2.

[3] Cahyadi, D. (2015). Analisa Perhitungan Efisiensi Turbine Generator QFSN-300-2-20B Unit 10 dan 20 PT. PJB UBJOM PLTU REMBANG. 1.

[4] Hidayat, A. (2018). Analisis pengaruh beban terhadap efisiensi generator PLTU PT. Lestari Banten Energi.

[5] Jepersen, S. (2016). Analisa Pengaruh Beban Terhadap Efisiensi Generator Sinkron Unit 1 di PLTU PT. Bukit Asam (Persero) Tbk Tanjung Enim-Sumatera Selatan. Palembang: Politeknik Negeri Sriwijaya.

[6] Marsudi, D. (2011). Pembangkitan Energi Listrik. Jakarta: Erlangga.

[7] Meidi. (2015). Pengaruh Perubahan Daya Terpasang Terhadap Efisiensi Generator 11 kV/20 MW Pada PLTG Unit 3 Keramasan PT. PLN (Persero) Palembang. Palembang: Politeknik Negeri Sriwijaya.

[8] Merle C. Potter, P. (n.d.). Termodinamika Teknik. Jakarta: Erlangga.

[9] Nurakmali, M. R. (2017). Analisis Efisiensi Generator Sinkron Unit 2 11,8 KV 55 MW Pembangkit Listrik Tenaga Panas Bumi PT. Indonesia Power UPJP Kamojang. Purbalingga.

[10] Setyawan, W. (2014). Analisa Pengaruh Beban Terhadap Efisiensi Generator PLTU di PT PJB Unit Pembangkitan Muara Karang. Jakarta: Universitas Mercu Buana.

[11] (2007). Teknologi Operasi PLTP. Jakarta: PT. PLN (Persero) Unit Pendidikan dan Pelatihan Suralaya.

[12] Jurnal, R. (2018). Kajian Pemasangan Lightning Arrester Pada Sisi Hv Transformator Daya Unit Satu Gardu Induk Teluk Betung. Energi \& Kelistrikan, 9(2), 168-179. https://doi.org/10.33322/energi.v9i2.42

[13] Jurnal, R. (2019). Kajian Sistem Kinerja Plts Off-Grid $1 \mathrm{kWp}$ DI STT PLN. Energi \& Kelistrikan, 10(1), 38-44. https://doi.org/10.33322/energi.v10i1.322

[14] Handayani, O., Darmana, T., \& Widyastuti, C. (2019). Analisis Perbandingan Efisiensi Penyaluran Listrik Antara Penghantar ACSR dan ACCC pada Sistem Transmisi 150kV. Energi \& Kelistrikan, 11(1), 37 - 45. https://doi.org/10.33322/energi.v11i1.480

[15] Jurnal, R. (2018). Pemanfaatan Radiasi Energi Tegangan $150 \mathrm{Kv}$ Untuk Lampu Led Penerangan Jalan. KILAT, 7(1), 51-55. 